\title{
Bicuspid aortic valve disease and pulmonary autograft root dilatation after the Ross procedure: A clinicopathologic study
}

\author{
Giovanni Battista Luciani, MDa \\ Luca Barozzi, MDa \\ Anna Tomezzoli, MD \\ Gianluca Casali, MDa \\ Alessandro Mazzucco, MDa
}

From the Divisions of Cardiac Surgery ${ }^{\mathrm{a}}$ and of Pathology, ${ }^{\mathrm{b}}$ University of Verona, Verona, Italy.

Received for publication Oct 10, 2000; revisions requested Dec 21, 2000; revision received Jan 3, 2001; accepted for publication Jan 25, 2001.

Address for reprints: Giovanni Battista Luciani, MD, Division of Cardiac Surgery, University of Verona, O. C. M. Piazzale Stefani 1, Verona 37126, Italy (E-mail: luciani@netbusiness.it).

J Thorac Cardiovasc Surg 2001;122:74-9

Copyright (C) 2001 by The American Association for Thoracic Surgery

$0022-5223 / 2001 \$ 35.00+0 \quad \mathbf{1 2} / \mathbf{1} / \mathbf{1 1 4 6 3 8}$

doi:10.1067/mtc.2001.114638
Objective: Bicuspid aortic valve disease has been associated with histologic abnormalities of the aortic root. Recent reports have suggested similar alterations may exist in the pulmonary artery of patients with bicuspid aortic valve. The present study was undertaken to define the histologic condition of the aortic and pulmonary artery root in bicuspid aortic valve disease and the relationship with pulmonary autograft root dilatation after the Ross procedure.

Methods: In 17 patients undergoing aortic root replacement with the pulmonary autograft, biopsy specimens of the aortic root and pulmonary artery trunk were collected. Clinical and histologic findings of patients with bicuspid aortic valves were compared with those with tricuspid aortic valves.

Results: There were 9 patients ( 8 male, 1 female) with bicuspid aortic valve (group 1) and 8 (all male) with tricuspid aortic valve (group 2). Mean age was comparable $(24.4 \pm 9.8$ vs $23.6 \pm 10.8$ years, $P=.9$ ). Aortic insufficiency as an indication for operation was more common in group 1 (9/9 vs $5 / 8, P=.007)$, whereas preoperative aortic root dilatation was equally prevalent $(4 / 9$ vs $1 / 8, P=.1)$. Prior aortic valve repair had been performed in 2 patients $(1 / 9$ vs $1 / 8, P=.9)$. Prevalence of cystic medionecrosis of the aortic wall was similar in the 2 groups $(4 / 9$ vs $3 / 8, P=.6)$. Cystic medionecrosis of the pulmonary artery trunk was found only in 1 patient with tricuspid aortic valve $(0 / 9$ vs $1 / 8, P=.3)$. During a mean follow-up of $26.5 \pm$ 12.2 months $(32.1 \pm 12.7$ vs $20.1 \pm 7.4$ months, $P=.04)$, prevalence of pulmonary autograft root dilatation (greater than $4.0 \mathrm{~cm}$ ) was equally represented in patients with native bicuspid or tricuspid aortic valve (3/9 vs $2 / 8, P=.6)$.

Conclusions: Histologic abnormalities of the pulmonary artery root are rare and equally prevalent in young patients with bicuspid and tricuspid aortic valves. On the contrary, root dilatation is relatively common late after autograft root replacement but appears unrelated to bicuspid aortic valve disease or to pre-existing degenerative changes of the pulmonary artery root.

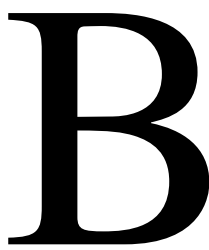

icuspid aortic valve is the most common cause of aortic valve disease leading to surgical treatment in children and young adults. ${ }^{1}$ A series of reports has shown greater prevalence of pathologic condition of the aorta, including aortic root aneurysm, annuloaortic ectasia, dissection, and coarctation, in patients with bicuspid aortic valve (BAV). ${ }^{2-5}$ An association between BAV disease and cystic medial necrosis of the aorta has been described, 
which can explain the relationship with aortic wall lesions. ${ }^{6}$ Yet, the question whether aortic wall abnormalities are secondary to valve disease, aging, or systemic hypertension ${ }^{7-9}$ or instead represent a malformation complex independent of these factors ${ }^{6,10}$ remains unanswered.

Because of the common embryogenesis of the aortic and pulmonary artery root, it has been suggested that the pulmonary artery wall may present changes similar to those found in the aorta. In a recent study ${ }^{11}$ a high prevalence of degenerative changes of the pulmonary artery media has been identified in patients with BAV. It has been hypothesized that this would explain the alleged tendency of pulmonary autograft roots to dilate after the Ross procedure in patients with BAV. ${ }^{12}$ However, a formal clinicopathologic study has not been undertaken. The goal of the present study is to correlate pathologic and clinical findings in patients with and without BAV undergoing the Ross procedure.

\section{Patients and Methods}

Between July 1994 and June 2000, 72 patients younger than 40 years of age underwent the Ross procedure at the University of Verona. The pulmonary autograft was inserted as a freehand subcoronary valve in 5 patients, an inclusion cylinder in 17, and a freestanding root in 50. On the basis of the preliminary observation showing that progressive root dilatation occurs in patients undergoing pulmonary autograft root replacement, ${ }^{12}$ the study was carried out only in the latter. Seventeen (34\%) of the patients undergoing aortic root replacement with the pulmonary autograft, 9 with BAV and 8 with tricuspid aortic valve (TAV), represent the population of the study. All patients had at least 1 year of follow-up available for analysis.

Comparison of demographic variables showed similar mean age and sex. All patients with BAV had pure aortic valve insufficiency as an indication for operation. Ascending aortic dilatation ( $4 \mathrm{~cm}$ or greater) was more common among patients with BAV, although not significantly. Other associated lesions were atrial septal defect, aneurysm of the membranous septum, and anomalous origin of the circumflex artery from the right coronary artery and bicuspid pulmonary valve, each in 1 patient. Only 2 patients had undergone prior operations, consisting of patch repair of ventricular septal defect and aortic valve resuspension in 1 and coarctation repair followed by open aortic valvotomy in the other (Table 1). One patient with severe mental delay and critical aortic stenosis associated with hypoplastic left ventricular outflow tract and sinotubular junction presented with bicuspid pulmonary valve at intraoperative examination. The valve had been described as tricuspid and competent at preoperative echocardiographic investigation. Because of the need for extended aortic root replacement and in the absence of an available biologic conduit, a decision was made to use the pulmonary autograft nonetheless. Follow-up echocardiographic examination showed absent autograft valve regurgitation 2 years after the operation.

Tissue samples of the aortic valve, aortic root, and pulmonary artery root were gathered from each patient at the time of operation. Samples of the main pulmonary artery were obtained $2 \mathrm{~cm}$ proximal to the sinotubular junction, where the wall was excised to host the coronary artery buttons. Samples of the aortic root were collected at the corresponding level. They were fixed in $10 \%$ buffered formalin solution. The tissue was processed for light microscopy, embedded in paraffin blocks, and sectioned out at 4- $\mu \mathrm{m}$ thickness from each specimen. Sections were stained with hematoxylin-eosin and elastictrichrome (modified elastic van Gieson). Each of the sections was evaluated histologically by 2 observers, 1 of them without any knowledge of the nature of the study. The histologic evaluation of the medial layer of the arterial wall was based on the presence of 4 variables: (1) fibrosis, (2) medionecrosis, (3) cystic medial necrosis (mucoid material accumulation), and (4) elastic fragmentation. Fibrosis was defined as an increase in the interstitial collagen. Medionecrosis was defined as focal loss of smooth muscle cell nuclei in the media. Cystic medial necrosis was defined as the accumulation of mucoid material or mucopolysaccharides in the presence of intact elastic lamellae and in the presence of fragmented elastic fibers. Elastic fragmentation was defined as focal fragmentation of elastic lamellae in the media of the aorta and pulmonary artery. Because of the limited patient population and the low prevalence of pathologic findings in the pulmonary artery specimens, no grading of the lesions was done.

Surgical technique consisted of freestanding aortic root replacement with routine buttressing of the inflow, outflow, and coronary button suture lines by using glutaraldehyde-fixed autologous pericardial strips as previously described. ${ }^{13}$ The purpose of this technical modification was both to confer greater hemostatic properties and to stabilize the aortic anulus and sinotubular junction diameters. Analysis of operative variables revealed comparable duration of cardiopulmonary bypass and aortic crossclamp in the 2 groups. Associated procedures consisted of reductive aortoplasty in the 5 patients with ascending aortic dilatation and patch repair of atrial septal defect and of membranous septal aneurysm, each in 1 patient. There were no hospital deaths. Perioperative complications were recorded in 3 patients. Two patients with BAV had acute right-sided heart failure due to ischemia of the right coronary-dependent myocardium. Takedown and reimplantation of the right coronary artery button in 1 patient and bypass grafting of the right coronary artery in the other allowed for intraoperative resolution of myocardial ischemia. The following clinical course was uneventful. A third patient with TAV exhibited moderate autograft valve regurgitation postoperatively requiring autograft valve repair during the same admission. Duration of assisted mechanical ventilation and intensive care and hospital stay was comparable in the 2 groups (Table 2).

Echocardiographic examination was carried out at 6 and 12 months and yearly thereafter. Autograft diameters were measured at 3 different levels by 2-dimensional echocardiography with the parasternal long-axis view, as previously described by Roman and colleagues. ${ }^{14}$ In brief, the anulus was measured at the level of the autograft leaflet hinges, the sinus of Valsalva at the largest anteroposterior diameter or $2 \mathrm{~cm}$ above the anulus level when the diameter of the sinotubular junction became identical or greater than the sinus, and the sinotubular junction at the distal rim of the sinus of Valsalva or $4 \mathrm{~cm}$ above the anulus in case of loss of geometry as specified above. 
TABLE 1. Demographic variables

\begin{tabular}{lccc}
\hline & $\begin{array}{c}\text { Bicuspid } \\
(\mathbf{n = 9})\end{array}$ & $\begin{array}{c}\text { Tricuspid } \\
(\mathbf{n}=\mathbf{8})\end{array}$ & $\boldsymbol{P}$ value \\
\hline Age (y) & $24.4 \pm 9.8$ & $23.6 \pm 10.8$ & .9 \\
$\begin{array}{l}\text { Male sex (patients) } \\
\begin{array}{c}\text { Preoperative aortic } \\
\text { insufficiency (patients) }\end{array}\end{array}$ & 8 & 8 & .3 \\
$\begin{array}{c}\text { Preoperative aortic root } \\
\text { dilatation (patients) }\end{array}$ & 9 & 5 & .007 \\
\begin{tabular}{l} 
Redo (patients) \\
\hline
\end{tabular} & 1 & 1 & .1 \\
\hline
\end{tabular}

Continuous variables were expressed as mean \pm SD and were compared by 2-tailed Student $t$ test for unpaired data. Categorical variables were expressed as proportions and compared by the Pearson $\chi^{2}$ or Fisher exact test as appropriate.

\section{Results}

\section{Aortic Valve}

All aortic valve specimens presented pathologic findings. Mucoid degeneration of the aortic valve was found in the majority $(11 / 17,65 \%)$ of patients and with similar distribution in the 2 patient groups. Fibrosis of the valve leaflets, often accompanied by calcification, was also common $(10 / 17,59 \%)$, either in isolated form (3 patients) or associated with mucoid degeneration (7 patients) (Table 3).

\section{Aortic Root}

All samples of aortic wall presented pathologic findings. Fibrosis was the most prevalent lesion $(13 / 17,76 \%)$, followed by cystic medionecrosis $(7 / 17,41 \%)$ and elastic fragmentation $(4 / 17,24 \%)$. The distribution of the histologic changes was comparable in the patients with BAV and TAV (Table 3).

\section{Pulmonary Artery Root}

Contrary to aortic wall samples, the majority $(12 / 17,71 \%)$ of pulmonary artery specimens were free of any pathologic finding and thus described as normal. Fibrosis $(2 / 17,12 \%)$ and elastic fragmentation $(2 / 17,12 \%)$ were found in a minority of patients and with similar distribution between the 2 groups. Changes compatible with cystic medionecrosis were identified in only 1 patient with TAV (Table 3 ). It is noteworthy that the patient with bicuspid pulmonary valve presented with normal pulmonary artery histologic findings.

\section{Autograft Dilatation and Function}

After an average follow-up of $26.5 \pm 12.2$ months, significantly longer in patients with BAV, autograft root dilatation ( 4.0 to $5.5 \mathrm{~cm}$ in diameter) was identified in 5 patients. Site of maximal root dilatation was the sinus of Valsalva in 3 patients and the sinotubular junction in 2. Prevalence of root
TABLE 2. Operative variables

\begin{tabular}{|c|c|c|c|}
\hline & $\begin{array}{l}\text { Bicuspid } \\
(n=9)\end{array}$ & $\begin{array}{c}\text { Tricuspid } \\
(\mathbf{n}=\mathbf{8})\end{array}$ & $P$ value \\
\hline $\begin{array}{l}\text { Aortic crossclamp time } \\
\text { (min) }\end{array}$ & $164.0 \pm 19.4$ & $159.4 \pm 30.4$ & .8 \\
\hline $\begin{array}{l}\text { Cardiopulmonary bypass time } \\
\text { (min) }\end{array}$ & $216.2 \pm 24.9$ & $192.8 \pm 12.6$ & .09 \\
\hline $\begin{array}{l}\text { Associated procedures } \\
\text { (patients) }\end{array}$ & 5 & 2 & .2 \\
\hline Complications (patients) & 2 & 1 & .5 \\
\hline Assisted ventilation (h) & $11.6 \pm 14.8$ & $8.9 \pm 6.2$ & .7 \\
\hline Intensive care unit stay (h) & $20.3 \pm 21.0$ & $16.3 \pm 12.8$ & .7 \\
\hline Hospital stay $(\mathrm{d})$ & $6.9 \pm 1.8$ & $7.0 \pm 1.1$ & .8 \\
\hline
\end{tabular}

dilatation in the study patients was greater than the estimate observed in the overall autograft root replacement patient population $(5 / 17,29 \%$ vs $9 / 50,18 \%)$. Autograft root dilatation was equally distributed in patients with BAV and TAV (Table 3). Of note, only 1 of 5 patients with autograft root dilatation had dilatation of the ascending aorta preoperatively. Analysis of autograft valve function showed absent to mild regurgitation in most $(15 / 17,88 \%)$ patients and moderate in 2 patients with dilatation of the sinotubular junction. Comparison of autograft valve function revealed no difference between patient groups (Table 3).

\section{Correlation Between Changes in the Aorta and Pulmonary Artery}

Of the 7 patients with cystic medionecrosis, elastic fragmentation, or both in the aortic root only 1 patient with TAV had similar changes in the pulmonary artery root. The remaining 6 had either normal histologic findings (5 patients) or mild fibrosis (1 patient) of the pulmonary artery. Thus, no correlation between degenerative changes in aorta and pulmonary artery could be established in the overall population or in the 2 patient groups.

\section{Correlation Between Pulmonary Artery Histology and Autograft Dilatation}

Only 1 of 5 patients with late autograft dilatation had cystic medionecrosis of the pulmonary artery. The remaining had either normal histologic findings ( 2 patients) or mild fibrosis ( 2 patients). No correlation between autograft dilatation and degenerative changes of the pulmonary artery root could be identified.

\section{Discussion}

BAV disease has been associated with pathologic conditions of the aorta for quite some time. ${ }^{2-5}$ Work by McKusick ${ }^{6}$ has shown the presence of degenerative changes of the aortic 
TABLE 3. Pathologic and clinical findings

\begin{tabular}{|c|c|c|c|}
\hline & Bicuspid $(n=9)$ & Tricuspid (n= 8) & $P$ value \\
\hline Mucoid degeneration of aortic valve (patients) & 6 & 5 & 6 \\
\hline Fibrosis of aortic valve (patients) & 4 & 6 & .3 \\
\hline Fibrosis of aortic root (patients) & 7 & 6 & 6 \\
\hline Cystic medionecrosis of aortic root (patients) & 4 & 3 & 6 \\
\hline Elastic fragmentation of aortic root (patients) & 1 & 3 & .3 \\
\hline Fibrosis of pulmonary root (patients) & 1 & 1 & .9 \\
\hline Cystic medionecrosis of pulmonary root (patients) & - & 1 & .3 \\
\hline Elastic fragmentation of pulmonary root (patients) & 1 & 1 & .9 \\
\hline Normal pulmonary root (patients) & 7 & 5 & .3 \\
\hline Follow-up (mo) & $32.1 \pm 12.7$ & $20.1 \pm 7.4$ & .04 \\
\hline \multicolumn{4}{|l|}{ Autograft valve regurgitation (patients) } \\
\hline Absent & 2 & 2 & \\
\hline Trace & 4 & 3 & \\
\hline Mild & 2 & 2 & \\
\hline Moderate & 1 & 1 & \\
\hline Severe & - & - & \\
\hline Autograft root dilatation $(>4 \mathrm{~cm}$ ) (patients) & 3 & 2 & 6 \\
\hline
\end{tabular}

wall medial layer in patients with BAVs. The ultimate origin of histologic lesions, whether due to a developmental error also responsible for the aortic valve malformation ${ }^{6}$ or due to the effects of valve dysfunction, age, or hypertension, ${ }^{7-9}$ remains a matter of speculation. Undoubtedly, cystic medial necrosis and elastic fragmentation represent nonspecific markers of degenerative aortic wall disease because these can be identified in young patients with Marfan syndrome as well as in aged normal subjects. Yet, the observation of degenerative changes in the aorta of patients with normally functioning bicuspid valves has lent some credence to the theory of a malformation complex. 2,3,10

Given the common embryogenesis of the aorta and pulmonary artery, it has been further hypothesized that similar histologic lesions could exist in the pulmonary artery media of patients with BAVs. ${ }^{11}$ In an attempt to explain the tendency of pulmonary autograft roots to dilate after the Ross procedure, de $\mathrm{Sa}$ and associates ${ }^{11}$ have defined the histologic structure of aorta and pulmonary artery in patients with BAVs and TAVs. Accordingly, a greater prevalence of degenerative changes of the media of the ascending aorta and of the main pulmonary artery has been found in patients with BAV disease. ${ }^{11}$

The present study is at variance with previous observations made by de $\mathrm{Sa}$ and coworkers ${ }^{11}$ because the vast majority of young patients undergoing aortic root replacement with the pulmonary autograft exhibit normal histologic structure of the pulmonary artery root. The low prevalence of pathologic findings in the pulmonary artery is similarly distributed in patients with BAVs and TAVs. Furthermore, no correlation has been found between late autograft root dilatation and BAV disease or pulmonary artery histologic lesions.
Our study differs from the work of de Sa and colleagues ${ }^{11}$ for a number of reasons, which may account for the apparent discrepancy in findings. Although it is based on a greater number of observations (31 vs 17 patients), mean age in the study by de $\mathrm{Sa}$ and colleagues is older than in the present study. In fact, only 13 of 31 patients with a mean age of 27 years are included in the work by de $\mathrm{Sa}$ and colleagues versus 17 in the current one. This difference is relevant because it is evident from previous studies that degenerative changes in the media of the aorta and, possibly, pulmonary artery are to some extent a function of age. ${ }^{9}$ In addition, the proportion of patients with aortic stenosis as an indication for valve replacement is larger in the series by de $\mathrm{Sa}$ and colleagues than in our own $(23 / 31,74 \%$ vs $3 / 17,18 \%, P=.002)$. Although this is unlikely to have any bearing in terms of pulmonary artery histologic type in the absence of significant pulmonary hypertension, ${ }^{11}$ it may explain the disparity in findings relative to aortic wall histologic characteristics. In fact, an association between hemodynamic changes, which are caused by aortic valve lesions, and macroscopic and microscopic lesions of the ascending aorta has long been established. ${ }^{7,8}$ Furthermore, site of tissue sampling differs significantly in the study of de Sa and colleagues and in the present one. Whereas samples of the aorta and pulmonary artery have been collected above the sinotubular junction (from the ascending aorta and main pulmonary artery) in the former study, specimens have been gathered below the sinotubular junction (aortic and pulmonary artery root) in the latter. Because aortic valve disease is often associated with ascending aortic dilatation, this may have led to overestimation of the prevalence of degenerative changes at the level of the aortic root in the 
series by de Sa and colleagues. In addition, because autograft root dilatation commonly presents at the sinus of Valsalva level, ${ }^{12,15}$ findings in the present study may be more pertinent to the problem than the ones in the study of de Sa and colleagues. Last but most important, the current work represents the only direct clinicopathologic analysis performed on patients who have actually undergone the Ross procedure. Contrary to the study by de Sa and colleagues, the present series has the potential to establish the association between pathologic variables of the aorta and pulmonary artery and the observed presentation of autograft root dilatation.

The prevalence of late aneurysm formation after the Ross procedure in the present series is somewhat higher than previously reported. ${ }^{12}$ When calculated for the entire series of patients undergoing aortic root replacement with pulmonary autografts, however, it matches the estimate found by David and associates ${ }^{12}(9 / 50,18 \%$ in the present study vs $13 / 71$, $18 \%$ in the one by David and associates). It is noteworthy that even the allegedly greater tendency of patients with $\mathrm{BAV}$ to experience autograft root dilatation ${ }^{12}$ is not confirmed by the present study. Our preliminary findings are in line with recent observations by Elkins ${ }^{16}$ on absence of correlation between aortic valve structure and late autograft dilatation in 350 patients. Similar to the report by David and colleagues, dilatation at the level of the sinus of Valsalva seems to cause limited autograft valve insufficiency. However, when dilatation of the sinotubular junction is predominant, valve regurgitation becomes relevant.

In the present study no correlation between BAV disease, degenerative changes of the pulmonary artery, and autograft root aneurysm has been identified. This suggests that factors other than pre-existing pathologic conditions of the pulmonary artery root must play a role in the appearance of autograft dilatation. Among these, degenerative lesions of the pulmonary artery media could conceivably occur after the autograft has been implanted as a consequence of its altered microvascular supply and of its exposure to the hemodynamic stress of the systemic circulation. This hypothesis is supported by previous observations showing that hypertension induces pathologic changes in the pulmonary artery media (cystic medionecrosis) identical to those caused in the aorta. ${ }^{17,18}$ In addition, variables relative to the operative technique may have an impact. Accordingly, strategies to manage associated ascending aortic dilatation, ${ }^{19}$ to stabilize the aortic anulus and/or sinotubular junction, ${ }^{19}$ and to support the pulmonary artery wall ${ }^{20,21}$ have gradually been introduced to reduce the prevalence of late aneurysm formation after root replacement. Although it seems evident that autograft dilatation is almost exclusively confined to the technique of freestanding aortic root replacement, ${ }^{12,22}$ uncertainty also exists regarding the long-term fate of native aortic root in which inclusion cylinders or freehand autografts are inserted. On this basis, the combination of aortic inclusion technique and fixation of both anulus and sinotubular junction has recently been proposed by David and coworkers. ${ }^{12}$ Only the test of time will prove the validity of these technical modifications.

\section{Limitations}

The present study has notable limitations. Choice of subjects who have entered the study was nonrandom, thus possibly biased. The population is small and follow-up is short, thereby allowing preliminary rather than definitive conclusions on the issue. Nevertheless, the patient population is rather homogeneous in the 2 groups. In addition, the present study is the only available clinicopathologic study in patients undergoing pulmonary autograft root replacement. Last, definition of pulmonary autograft root dilatation of 4 $\mathrm{cm}$ or greater as root aneurysm may be arbitrary, because prior work has shown that sinus of Valsalva diameter can occasionally reach this dimension in normal individuals. ${ }^{22}$ However, it must be considered that $4 \mathrm{~cm}$ represents the maximum sinus diameter plus 2 standard deviations. Furthermore, the latter measure has been previously used as cutoff value for identification of significant autograft root dilatation by David and associates. ${ }^{11,12}$ A choice has therefore been made to maintain this parameter to appropriately compare the present results.

In conclusion, prevalence of degenerative changes of the pulmonary artery root is negligible and similar in patients with BAV and TAV undergoing the Ross procedure. Late autograft root dilatation appears unrelated to BAV disease or pre-existing histologic lesions of the pulmonary artery.

\section{References}

1. Peterson MD, Roach RM, Edwards JE. Types of aortic stenosis in surgically removed valves. Arch Pathol Lab Med. 1985;109:829-33.

2. Pachulski RT, Weinberg AL, Chan KL. Aortic aneurysm in patients with functionally normal or minimally stenotic bicuspid aortic valve. Am J Cardiol. 1991;67:781-2.

3. Hahn RT, Roman MJ, Mogtader AH, Devereux RB. Association of aortic root dilation with regurgitant, stenotic and functionally normal bicuspid aortic valves. J Am Coll Cardiol. 1992;19:283-8.

4. Gore I. Dissecting aneurysms of the aorta in persons under forty years of age. Arch Pathol. 1953;55:1-13.

5. Abbott ME. Coarctation of the aorta of the adult type. Am Heart J. 1928;3:381-421.

6. McKusick VA. Association of congenital bicuspid aortic valve and Erdheim's cystic medial necrosis. Lancet. 1972;1:1026-7.

7. Holman E. The obscure physiology of post-stenotic dilatation: its relation to the development of aneurysms. J Thorac Surg. 1954;28:109-33.

8. Stebhens WE. Structural and architectural changes during arterial development and the role of hemodynamics. Acta Anat. 1996;157:26174.

9. Carlson RG, Lillehei CW, Edwards JE. Cystic medial necrosis of the ascending aorta in relation to age and hypertension. Am J Cardiol. 1970;25:411-5.

10. Larson EW, Edwards WD. Risk factors for aortic dissection: a necropsy study of 161 cases. Am J Cardiol. 1984;53:849-55. 
11. de Sa MPL, Moshkovitz Y, Butany J, David TE. Histologic abnormalities of the ascending aorta and pulmonary trunk in patients with bicuspid aortic valve disease: clinical relevance to the Ross procedure. J Thorac Cardiovasc Surg. 1999;118:588-94.

12. David TE, Omran A, Ivanov J, Armstrong S, de Sa MPL, Sonnenberg $\mathrm{B}$, et al. Dilatation of the pulmonary autograft after the Ross procedure. J Thorac Cardiovasc Surg. 2000;119:210-20.

13. Luciani GB, Casali G, Santini F, Mazzucco A. Aortic root replacement in adolescents and young adults: composite graft versus homograft and autograft. Ann Thorac Surg. 1998;66:S189-93.

14. Roman MJ, Devereux RB, Kramer-Fox R, O'Loughlin J. Two-dimensional echocardiographic aortic root dimensions in normal children and adults. Am J Cardiol. 1989;64:507-12.

15. Hokken RB, Bogers AJJ, Taams MA, et al. Does the pulmonary autograft in the aortic position in adults increase in diameter? An echocardiographic study. J Thorac Cardiovasc Surg. 1998;113:667-74.

16. Elkins RC. Discussion of David et al. ${ }^{12}$
17. Tredal SM, Carter JB. Cystic medial necrosis of the pulmonary artery. Arch Pathol. 1974;97:183-6.

18. Butto F, Lucas R, Edwards J. Pulmonary arterial aneurysm: a pathologic study of five cases. Chest. 1987;91:237-41.

19. Elkins RC, Lane MM, McCue C, Chandrasekaran K. Ross operation and aneurysm or dilation of the ascending aorta. Semin Thorac Cardiovasc Surg. 1999;11(suppl 1):50-4.

20. Pacifico AD, Kriklin JK, McGiffin DC, Matter GJ, Nanda NC, Diethelm AG. The Ross procedure: early echocardiographic comparison of different operative techniques. J Heart Valve Dis. 1994;3:365-70.

21. Moritz A, Domanig E, Marx M, Moidl R, Simon P, Laufer G, et al. Pulmonary autograft valve replacement in the dilated and asymmetric aortic root. Eur J Cardiothorac Surg. 1993;7:405-8.

22. Schmidtke C, Bechtel JFM, Hueppe M, Noetzold A, Sievers HH. Size and distensibility of the aortic root and aortic valve function after different techniques of the Ross procedure. $J$ Thorac Cardiovasc Surg. 2000;119:990-7.

\section{Bound volumes available to subscribers}

Bound volumes of The Journal of Thoracic and Cardiovascular Surgery are available to subscribers (only) for the 2001 issues from the Publisher, at a cost of \$134.00 for domestic, \$165.85 for Canadian, and \$155.00 for international subscribers for Vol 121 (January-June) and Vol 122 (July-December). Shipping charges are included. Each bound volume contains a subject and author index and all advertising is removed. Copies are shipped within 60 days after publication of the last issue of the volume. The binding is durable buckram with the Journal name, volume number, and year stamped in gold on the spine. Payment must accompany all orders. Contact Mosby, Subscription Customer Service, 6277 Sea Harbor Dr, Orlando, FL 32887, USA; phone 800-654-2452 or 407-345-4000.

Subscriptions must be in force to qualify. Bound volumes are not available in place of a regular Journal subscription. 